\title{
Article \\ Does a Vegetarian Diet Affect the Levels of Myokine and Adipokine in Prepubertal Children?
}

\author{
Jadwiga Ambroszkiewicz ${ }^{1, *(\mathbb{D}}$, Joanna Gajewska ${ }^{1}\left(\mathbb{D}\right.$, Joanna Mazur $^{2}{ }^{(0)}$, Witold Klemarczyk ${ }^{3}$, \\ Grażyna Rowicka ${ }^{3}{ }^{-}$, Mariusz Ołtarzewski ${ }^{1}$, Małgorzata Strucińska ${ }^{3}$ and Magdalena Chełchowska ${ }^{1}{ }^{10}$ \\ 1 Department of Screening Tests and Metabolic Diagnostics, Institute of Mother and Child, 01-211 Warsaw, \\ Poland; joanna.gajewska@imid.med.pl (J.G.); mariusz.oltarzewski@imid.med.pl (M.O.); \\ magdalena.chelchowska@imid.med.pl (M.C.) \\ 2 Department of Humanization in Medicine and Sexology, Collegium Medicum, University of Zielona Gora, \\ 65-726 Zielona Gora, Poland; j.mazur@cm.uz.zgora.pl \\ 3 Department of Nutrition, Institute of Mother and Child, 01-211 Warsaw, Poland; \\ witold.klemarczyk@imid.med.pl (W.K.); grazyna.rowicka@imid.med.pl (G.R.); \\ malgorzata.strucinska@imid.med.pl (M.S.) \\ * Correspondence: jadwiga.ambroszkiewicz@imid.med.pl; Tel.: +48-22-3277-260; Fax: +48-22-3277-161
}

Citation: Ambroszkiewicz, J.; Gajewska, J.; Mazur, J.; Klemarczyk, W.; Rowicka, G.; Ołtarzewski, M.; Strucińska, M.; Chełchowska, M. Does a Vegetarian Diet Affect the Levels of Myokine and Adipokine in Prepubertal Children? J. Clin. Med. 2021, 10, 3995. https://doi.org/ $10.3390 /$ jcm10173995

Academic Editors: Muh-Shi Lin, Emmanuel Andrès and Pawel K. Olszewski

Received: 29 June 2021

Accepted: 2 September 2021

Published: 3 September 2021

Publisher's Note: MDPI stays neutral with regard to jurisdictional claims in published maps and institutional affiliations.

Copyright: (c) 2021 by the authors. Licensee MDPI, Basel, Switzerland. This article is an open access article distributed under the terms and conditions of the Creative Commons Attribution (CC BY) license (https:// creativecommons.org/licenses/by/ $4.0 /)$.

\begin{abstract}
Myokines are cytokines secreted by muscle and exert autocrine, paracrine, or endocrine effects. Myokines mediate communication between muscle and other organs, including adipose tissue. The aim of the study was to assess serum myokines and their relationships with adipokines and anthropometric and nutritional parameters in children following vegetarian and omnivorous diets. One hundred and five prepubertal children were examined. Among them there were 55 children on a vegetarian diet and 50 children on an omnivorous diet. Concentrations of myokines (myostatin, irisin) and adipokines (leptin, adiponectin, omentin, visfatin) in serum were determined by enzyme-linked immunosorbent assay (ELISA). We observed comparable median values of serum myokines and adipokines (except of leptin concentration) in both of the studied groups of children. We also found several correlations between myokine and adipokine levels and certain nutritional parameters. Serum myostatin was positively correlated with omentin levels in vegetarians and omnivores $(p=0.002)$. Serum irisin was positively associated with omentin $(p=0.045)$ levels in omnivores and inversely with visfatin concentration $(p=0.037)$ in vegetarians. Myostatin concentration was negatively correlated with the percentage of energy from protein $(p=0.014)$, calcium $(p=0.046)$, and vitamin A $(p=0.028)$ intakes in vegetarians and with dietary vitamin $C(p=0.041)$ and vitamin $\mathrm{E}(p=0.021)$ intakes in omnivores. In multivariate regression analyses, positive correlations of serum myostatin with omentin levels were revealed in both study groups $(\beta=0.437, p<0.001$ for vegetarians; and $\beta=0.359$, $p=0.001$ for omnivores). Consuming a lacto-ovo-vegetarian diet did not influence serum levels of myokines (myostatin, irisin) and adipokines such as adiponectin, visfatin, and omentin in prepubertal children. However, leptin levels were significantly lower in vegetarians compared with omnivores. The observed significant positive correlations between myostatin and omentin concentrations might suggest tissue cross-talk between skeletal muscle and fat tissue. Further studies, carried out in a larger group of children following different dietary patterns, could be important to fully understand the relations between muscle, adipose tissues, and nutrition.
\end{abstract}

Keywords: myostatin; irisin; omentin; visfatin; lacto-ovo-vegetarian diet

\section{Introduction}

A proper diet is one of the important factors that determine age-appropriate body weight and body composition, including fat, lean, and bone mass, which is why children's diets should be safe and prevent nutrient deficiencies [1,2]. Recently, many vegetarian parents want their children to adopt their diet [3-5]. The lacto-ovo-vegetarian diet, which 
includes milk, milk products, and eggs is the most common variant. Generally, a wellbalanced plant-based diet with an adequate intake of high-quality protein, calcium, and vitamins (especially $B_{12}$ and D) can satisfy all the nutritional needs of a growing child [6,7].

Both muscle and fat tissues are endocrine organs that secrete many biologically active factors, known as myokines and adipokines, implicated in the regulation of energy homeostasis and metabolism [8,9]. Myokines are cytokines produced by muscle fibers (myocytes), mainly in response to physical activity. Among them, myostatin and irisin appear to have promising clinical value. Myostatin, a protein belonging to the family of transforming $\beta$ growth factor (TGF- $\beta$ ), plays a role in the regulation of skeletal muscle mass through myoblast proliferation and differentiation [10-13]. Another myokine, irisin, is a peptide (112-123 amino acids, $22 \mathrm{kDa}$ ) cleaved from the extracellular domain of Fndc5 (fibronectin type III domain containing proteins 5) by stimulation with PGC- $1 \alpha$ (peroxisome proliferator-activated receptor gamma coactivator 1- $\alpha$ ), expressed in skeletal muscle and other tissues $[14,15]$. Recent experimental and observational studies have indicated that irisin is a myokine that induces white adipose tissue browning, energy expenditure, improved glucose tolerance, and enhanced thermogenesis $[16,17]$. Besides its hormonal function, it may act as a transmembrane signaling protein that mediates the cross-talk of skeletal muscle to other tissues; however, this hypothesis remains to be confirmed [18]. It is important to note that irisin is not a protein exclusively secreted by muscle tissue. It is also secreted by white adipose tissue; thus, irisin is not only a myokine but also an adipokine.

Apart from the well-known adipokines, such as leptin and adiponectin, fat tissue also releases other adipokines, including visfatin and omentin. Visfatin, expressed mainly by visceral adipose tissue, regulates adipocyte differentiation and is involved in the control of weight [19]. Serum visfatin concentrations depend on lifestyle interventions, including exercise and diet. As a multifunctional protein, visfatin may act as a hormone, cytokine, and enzyme-nicotinamide phosphoribosyltransferase (Nampt) [20]. Omentin is an adipokine that has anti-inflammatory properties. It plays a role in adipocyte differentiation and maturation, metabolism and immune response regulation, inflammation, and insulin resistance [21]. Its decreased level was observed in obese compared with lean subjects, suggesting that omentin concentration may be predictive of the metabolic consequences associated with obesity [22].

The relationships between muscle and adipose tissues are very important $[23,24]$, especially in children who are in the developmental period. Many studies have shown the beneficial effects of a plant-based diet on decreased risk of several diseases, but the underlying mechanisms for this influence are not fully understood $[25,26]$. No data exist concerning myokines levels and their relations with the adipokine profile in vegetarians.

The aim of this study was to assess serum concentrations of myokines (myostatin, irisin) and to analyze their relationships with some adipokine levels and anthropometric and nutritional parameters in children with different eating styles: vegetarians and omnivores.

\section{Materials and Methods}

\subsection{Subjects}

We examined 105 prepubertal healthy children. All studied children were Caucasians. Among them, there were 55 (52.7\% male, $47.3 \%$ female, age 5-9 years) children on a vegetarian diet. The inclusion criteria were: being in the prepubertal period, on a lacto-ovovegetarian diet from birth, apparently healthy without disorders in terms of development and nutrition. The exclusion criteria were: low birth weight, gastrointestinal diseases, nutrition disorders, and regular medication consumption, except for standard vitamin $\mathrm{D}$ supplementation. The pubertal stage was assessed according to Tanner's criteria. We recruited the maximum possible number of prepubertal children who consumed a lactoovo-vegetarian diet attending the Department of Nutrition at the Institute of Mother and Child in Warsaw between May 2018 and January 2020. 
The control group included 50 healthy children (48.0\% male, 52\% female) aged 5-9 years on a traditional omnivorous diet, which consisted of consuming meat, poultry, and fish. Health status was assessed by collecting medical history data and conducting a basic physical examination.

The studied children (vegetarians and omnivores) were attaining the World Health Organization's recommendation regarding physical activity. They accumulated about 60-90 min/day of MVPA (moderate-to-vigorous physical activity) and approximately $30 \mathrm{~min} /$ day of VPA (vigorous physical activity). VPA included activities after school twice a week for 1 or $2 \mathrm{~h}$. The level of physical activity was similar in both of the studied groups of children.

The protocol of this study was in accordance with the Helsinki Declaration of Principles and approved by the Ethics Committee of the Institute of Mother and Child (decision number 12/2017, 12 March, 2017). All children's parents were informed about the study procedures and all signed a written consent prior to the start of the study.

\subsection{Methods}

Measurements of body weight and height were performed, and body mass index (BMI) was calculated as body weight $(\mathrm{kg})$ divided by height squared $\left(\mathrm{m}^{2}\right)$. Body composition (fat mass, lean mass, bone mineral content-BMC) was measured by dual-energy X-ray absorptiometry (DXA) using Lunar Prodigy (General Electric Healthcare, Madison, WI, USA).

As described in more detail in a previous article [27], the dietary assessment was analyzed using the nutritional software program Dieta $5^{\circledR}$ (National Food and Nutrition Institute, Warsaw). The parents of the studied children were advised by a nutritionist and asked to prepare a food diary for their children. Three dietary recalls (two weekdays and one weekend day) were performed to evaluate the dietary habits. Average daily energy intake; percentage of energy from dietary protein, fat and carbohydrates, and fiber; and mineral and vitamin intakes were assessed in the studied children.

Blood samples were obtained from the children in the morning after an overnight fast. The serum samples were obtained and frozen at $-20{ }^{\circ} \mathrm{C}$ until analysis. Concentrations of serum myokines and adipokines were determined by commercial enzyme-linked immunosorbent assay (ELISA), according to the manufacturer's instructions. Serum irisin level was assayed using the kit from BioVendor (Brno, Czech Republic). The limit of detection in this method was $1 \mathrm{ng} / \mathrm{mL}$; intra-assay and inter-assay coefficients of variation (CV) were 4.9-8.2\% and 8.0-0.7\%, respectively. Myostatin concentration was determined using the kit from SunRed Biotechnology (Shanghai, China) with a limit of detection of $5.11 \mathrm{ng} / \mathrm{L}$, and intra-assay and inter-assay of precision less than $8 \%$ and $11 \%$, respectively. Concentration of leptin was assessed using kit from DRG Instruments GmbH (Marburg, Germany) with an analytical sensitivity of $0.2 \mathrm{ng} / \mathrm{mL}$; intra-assay CV ranged between 4.2 and $7.3 \%$ and inter-assay CV ranged between 3.7 and 9.1\%. Level of total adiponectin was measured using a kit from TECOmedical AG (Sissach, Switzerland), with the lower detection limit of $0.6 \mu \mathrm{g} / \mathrm{mL}$; intra-assay CV: $2.35-4.66 \%$, inter-assay CV: $5.70-6.72 \%$. Serum visfatin level was detected using the Nampt (Visfatin/PBEF) kit from Adipogen Life Science (Liestal, Switzerland). The lowest level of Nampt visfatin that can be detected by this assay was $30 \mathrm{pg} / \mathrm{mL}$; the intra-assay precision was $2.31-9.11 \%$ and the inter-assay precision was $4.66-7.24 \%$. Serum omentin was measured using the kit from SunRed Biotechnology (Shanghai, China), with a sensitivity of $5.22 \mathrm{ng} / \mathrm{mL}$; intra-assay CV was less than 10\%, and inter-assay CV was less than $12 \%$.

\subsection{Statistical Analyses}

All analyses were carried out using IBM-SPSS software version 23.0 (SPSS INC., Chicago, IL, USA). The normality of the distribution of the variables was checked using the Kolmogorov-Smirnov test. To compare categorical data, the chi-squared test was used. Data were described as mean values and standard deviation (SD) for the variables with 
normal distribution, or as median values and interquartile ranges (1Q-3Q) for non-normally distributed variables. For group comparisons, the Student's t-test was used when data were normally distributed, and the Mann-Whitney U test was used for non-parametric variables. Significance was accepted when the $p$-value was $<0.05$. Correlation analysis was performed using the Spearman test and interpreted with Bonferroni correction (threshold $p$-value of 0.002).

A series of multivariate linear regression models were estimated separately for serum levels of myostatin and irisin. In the first step, an ordinary least square method of estimation was applied. All available data were considered as potential predictors; in total there were 23 variables representing: other myokines, adipokines, and anthropometric and nutritional parameters. To find an optimal set of predictors, a stepwise selection strategy was chosen. After each step, in which a new variable was added, all variables accepted previously were checked in terms of their significance. The cut-off points were less rigorous than usual ( 0.10 for entry and 0.15 for removal) to check the effect of predictors close to the significance level (more than 0.05 but less than 0.10 ). This facilitated finding more predictors with a significant contribution to the variability of dependent variables, despite relatively weaker significance. The results were presented as both standardized and unstandardized parameters. The change of $\mathrm{R}^{2}$ was considered an important goodness of fit statistic. In the second step, the same independent variables were included in the generalized linear models (GLM) with skewed link function $\gamma$, and $p$-values were compared. In GLM models, the maximum likelihood method of estimation is employed, and an other than normal distribution of the dependent variable is accepted. In addition, two GLM models, estimated on the combined sample, were added as supplementary electronic material. They included dietary group as a factor and all variables accepted in the previous stage as covariates. The significance of the main effect and 2-way interactions between dietary groups and covariates were tested.

\section{Results}

Both groups of children were comparable in terms of age and anthropometric parameters (Table 1$)$. In vegetarians, we noted significantly lower $(p=0.018)$ fat mass than in omnivorous peers.

Table 1. Anthropometric parameters in children on vegetarian and omnivorous diets.

\begin{tabular}{|c|c|c|c|}
\hline Variables & Vegetarians $(n=55)$ & Omnivores $(n=50)$ & $p$ \\
\hline Age (years) ${ }^{b}$ & $5.5(5.0-7.0)$ & $6.0(5.0-8.0)$ & 0.147 \\
\hline Body weight $(\mathrm{kg})^{\text {a }}$ & $20.70 \pm 3.87$ & $21.22 \pm 5.86$ & 0.723 \\
\hline Height $(\mathrm{cm})^{\mathrm{a}}$ & $117.39 \pm 10.42$ & $118.58 \pm 10.89$ & 0.544 \\
\hline $\operatorname{BMI}\left(\mathrm{kg} / \mathrm{m}^{2}\right)^{\mathrm{a}}$ & $14.76 \pm 0.92$ & $14.66 \pm 1.44$ & 0.070 \\
\hline Fat mass $(\mathrm{kg})^{b}$ & $3.32(2.67-4.35)$ & $3.94(3.10-5.30)$ & 0.018 \\
\hline Fat $(\%) b^{b}$ & $18.80(14.80-22.40)$ & 21.55 (17.15-24.23) & 0.057 \\
\hline Lean mass $(\mathrm{kg})^{\mathrm{b}}$ & $14.80(13.55-16.88)$ & 15.81 (12.77-19.52) & 0.349 \\
\hline Fat/lean mass $b$ & $0.233(0.173-0.301)$ & $0.272(0.200-0.321)$ & 0.114 \\
\hline $\operatorname{BMC}(g)^{a}$ & $668.7 \pm 177.6$ & $697.0 \pm 237.8$ & 0.103 \\
\hline
\end{tabular}

Data are presented as ${ }^{\mathrm{a}}$ mean values and standard deviation (SD) and ${ }^{\mathrm{b}}$ median values and interquartile ranges (1Q-3Q); BMI—body mass index, BMC—bone mineral content.

Analyzing the children's diets, we observed similar daily energy intake in both groups of children, whereas the proportions of macronutrient intakes in vegetarians and omnivores were different (Table 2). Vegetarians had a significantly higher percentage of energy from carbohydrates $(p=0.002)$, a lower percentage of energy from protein $(p<0.001)$, and a similar percentage of energy from fat $(p=0.166)$ compared with omnivores. Among minerals, vegetarians had a comparable intakes of phosphorus $(\mathrm{P})$, magnesium $(\mathrm{Mg})$, and calcium $(\mathrm{Ca})$ but a significantly higher intake of manganese $(\mathrm{Mn})(p=0.020)$. In terms of vitamins, children on a vegetarian diet had a significantly lower intake of vitamin 
$\mathrm{B}_{12}(p<0.001)$ and a higher intake of vitamin $\mathrm{C}(p=0.019)$. No statistically significant differences in dietary intakes of vitamin $\mathrm{A}, \mathrm{D}$, and $\mathrm{E}$ in both groups were found.

Table 2. Dietary intake of macro- and micronutrients in children on vegetarian and omnivorous diets.

\begin{tabular}{|c|c|c|c|}
\hline Variables & Vegetarians $(n=55)$ & Omnivores $(n=50)$ & $p$ \\
\hline 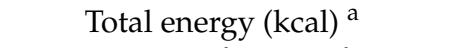 & $1404.6 \pm 393.1$ & $1590.5 \pm 500.9$ & 0.470 \\
\hline $\begin{array}{l}\text { Percentage of energy from } \\
\text { protein } b\end{array}$ & $11.5(10.3-13.1)$ & $13.6(11.6-15.0)$ & $<0.001$ \\
\hline Percentage of energy from fat ${ }^{b}$ & $31.1(27.6-34.6)$ & $33.3(28.1-37.1)$ & 0.166 \\
\hline $\begin{array}{l}\text { Percentage of energy from } \\
\text { carbohydrates } b\end{array}$ & $56.7(53.3-61.3)$ & $52.9(49.3-58.0)$ & 0.002 \\
\hline Fiber (g/day) ${ }^{a}$ & $19.0 \pm 8.3$ & $16.0 \pm 6.1$ & 0.063 \\
\hline Calcium (mg/day) ${ }^{b}$ & $513.3(311.9-641.3)$ & $604.0(404.9-778.0)$ & 0.056 \\
\hline Phosphorus (mg/day) ${ }^{b}$ & $841.2(597.7-1011.4)$ & 868.5 (707.9-1017.2) & 0.161 \\
\hline Magnesium (mg/day) ${ }^{b}$ & $223.5(174.2-320.2)$ & $216.7(170.2-260.3)$ & 0.633 \\
\hline Manganese (mg/day) ${ }^{b}$ & $3.49(2.33-4.37)$ & $2.54(1.89-3.52)$ & 0.020 \\
\hline Vitamin A ( $\mu \mathrm{g} /$ day $)^{\mathrm{b}}$ & $897.6(658.8-1447.6)$ & $837.8(589.2-1298.1)$ & 0.203 \\
\hline Vitamin $B_{12}(\mu g / \text { day })^{b}$ & $1.44(0.90-2.12)$ & $2.31(1.80-3.78)$ & $<0.001$ \\
\hline Vitamin C (mg/day) ${ }^{b}$ & $79.8(44.8-122.3)$ & $68.7(47.8-103.3)$ & 0.019 \\
\hline Vitamin E (mg/day) ${ }^{b}$ & $9.50(6.94-11.81)$ & $8.04(6.03-11.68)$ & 0.315 \\
\hline Vitamin $D(\mu g / \text { day })^{b}$ & $1.73(0.82-4.15)$ & $2.12(1.01-5.63)$ & 0.058 \\
\hline
\end{tabular}

Data are presented as ${ }^{\mathrm{a}}$ mean values and standard deviation (SD) and ${ }^{\mathrm{b}}$ median values and interquartile ranges $(1 \mathrm{Q}-3 \mathrm{Q})$.

As shown in Table 3, there are no statistically significant differences in the median values of serum myostatin and irisin concentrations or in the levels of adipokines such as visfatin, omentin, and adiponectin between vegetarians and omnivores. However, leptin concentration was significantly lower in vegetarian compared with omnivorous children.

Table 3. Serum concentrations of myokines and adipokines in vegetarian and omnivorous children.

\begin{tabular}{cccc}
\hline Variables & Vegetarians & Omnivores & $p$ \\
\hline Myostatin $(\mathrm{ng} / \mathrm{mL})$ & $0.82(0.52-1.19)$ & $0.58(0.47-1.01)$ & 0.131 \\
Irisin $(\mu \mathrm{g} / \mathrm{mL})$ & $3.05(2.00-4.40)$ & $2.79(2.24-4.02)$ & 0.957 \\
Nampt visfatin $(\mathrm{ng} / \mathrm{mL})$ & $1.82(0.77-2.85)$ & $1.44(0.89-3.056)$ & 0.969 \\
Omentin $(\mathrm{ng} / \mathrm{mL})$ & $504.7(295.3-1156.9)$ & $386.2(263.9-1010.8)$ & 0.149 \\
Leptin $(\mathrm{ng} / \mathrm{mL})$ & $1.39(0.80-1.90)$ & $2.05(1.22-2.80)$ & 0.003 \\
Adiponectin $(\mu \mathrm{g} / \mathrm{mL})$ & $8.76(7.27-11.60)$ & $7.95(6.61-10.03)$ & 0.059 \\
\hline
\end{tabular}

Data are presented as median values and interquartile ranges (1Q-3Q).

Assessing simple correlations, we found significant associations between myokine and adipokine levels, including a strong positive association between serum myostatin and omentin levels in both groups of children $(\mathrm{r}=0.415, p=0.002$ and $\mathrm{r}=0.455, p=0.002$, respectively) (Table 4). Additionally, we observed, only in omnivores, a weak positive association between irisin and omentin concentrations $(r=0.300, p=0.045)$ and, only in vegetarians, an inverse correlation between irisin and Nampt visfatin levels $(\mathrm{r}=-0.282$, $p=0.037$ ). We did not notice significant correlations between classical adipokines (leptin, adiponectin) and myokines levels. Concerning the anthropometric data, we noted significant positive correlations between myostatin level and body fat percentage in omnivores $(\mathrm{r}=0.402, p=0.004)$ and weak negative correlations of irisin levels with lean mass $(\mathrm{r}=-0.266, p=0.049)$ and BMC $(\mathrm{r}=-0.269, p=0.047)$ in vegetarians. No significant associations between myokine concentrations and other anthropometric parameters were found in either group of children. 
Table 4. Spearman's correlations of myokine concentrations with anthropometric parameters, nutritional parameters, and adipokine levels in vegetarian and omnivorous children.

\begin{tabular}{|c|c|c|c|c|c|c|c|c|}
\hline \multirow{3}{*}{ Variables } & \multicolumn{4}{|c|}{ Vegetarians } & \multicolumn{4}{|c|}{ Omnivores } \\
\hline & \multicolumn{2}{|c|}{ Myostatin } & \multicolumn{2}{|c|}{ Irisin } & \multicolumn{2}{|c|}{ Myostatin } & \multicolumn{2}{|c|}{ Irisin } \\
\hline & $\mathbf{r}$ & $p$ & $\mathbf{r}$ & $p$ & $\mathbf{r}$ & $p$ & $\mathbf{r}$ & $p$ \\
\hline \multicolumn{9}{|c|}{ Anthropometric parameters: } \\
\hline BMI & 0.116 & 0.397 & 0.125 & 0.364 & 0.021 & 0.888 & -0.088 & 0.544 \\
\hline Fat mass & -0.002 & 0.989 & 0.081 & 0.555 & 0.105 & 0.466 & 0.038 & 0.791 \\
\hline Fat $(\%)$ & 0.070 & 0.609 & 0.103 & 0.452 & 0.402 & 0.004 & -0.077 & 0.594 \\
\hline Lean mass & -0.019 & 0.890 & -0.266 & 0.049 & 0.015 & 0.917 & 0.221 & 0.122 \\
\hline Fat/lean mass ratio & 0.020 & 0.882 & 0.133 & 0.334 & 0.090 & 0.536 & -0.113 & 0.435 \\
\hline $\mathrm{BMC}$ & -0.146 & 0.289 & -0.269 & 0.047 & -0.009 & 0.952 & 0.073 & 0.615 \\
\hline \multicolumn{9}{|c|}{ Nutritional parameters: } \\
\hline Total energy intake & 0.029 & 0.840 & 0.185 & 0.189 & -0.048 & 0.752 & -0.100 & 0.515 \\
\hline Percentage of energy from protein & -0.338 & 0.014 & -0.128 & 0.366 & 0.113 & 0.460 & -0.118 & 0.441 \\
\hline Percentage of energy from fat & 0.083 & 0.559 & -0.208 & 0.140 & -0.294 & 0.050 & 0.017 & 0.914 \\
\hline Percentage of energy from carbohydrates & 0.045 & 0.753 & 0.254 & 0.070 & 0.243 & 0.108 & 0.086 & 0.574 \\
\hline Dietary fiber & -0.015 & 0.919 & 0.042 & 0.770 & -0.063 & 0.681 & 0.037 & 0.810 \\
\hline Dietary calcium & -0.278 & 0.046 & 0.105 & 0.457 & 0.128 & 0.403 & -0.016 & 0.919 \\
\hline Dietary phosphorus & -0.100 & 0.480 & 0.169 & 0.231 & 0.067 & 0.660 & -0.159 & 0.296 \\
\hline Dietary magnesium & 0.021 & 0.883 & 0.187 & 0.184 & 0.011 & 0.945 & -0.231 & 0.127 \\
\hline Dietary manganese & 0.101 & 0.475 & 0.005 & 0.972 & 0.030 & 0.844 & -0.160 & 0.295 \\
\hline Dietary vitamin A & -0.304 & 0.028 & -0.013 & 0.925 & -0.040 & 0.759 & 0.233 & 0.129 \\
\hline Dietary vitamin $B_{12}$ & -0.207 & 0.140 & 0.049 & 0.731 & 0.085 & 0.579 & -0.070 & 0.649 \\
\hline Dietary vitamin C & 0.034 & 0.810 & 0.192 & 0.173 & -0.306 & 0.041 & 0.044 & 0.776 \\
\hline Dietary vitamin D & -0.161 & 0.254 & 0.044 & 0.755 & -0.149 & 0.329 & 0.102 & 0.505 \\
\hline Dietary vitamin E & 0.155 & 0.272 & -0.006 & 0.965 & -0.343 & 0.021 & -0.089 & 0.562 \\
\hline \multicolumn{9}{|c|}{ Adipokines: } \\
\hline Omentin & 0.415 & 0.002 & -0.072 & 0.603 & 0.455 & 0.002 & 0.300 & 0.045 \\
\hline Nampt visfatin & -0.015 & 0.912 & -0.282 & 0.037 & -0.094 & 0.515 & -0.214 & 0.135 \\
\hline Leptin & 0.053 & 0.701 & -0.036 & 0.796 & 0.162 & 0.618 & 0.114 & 0.431 \\
\hline Adiponectin & 0.005 & 0.973 & -0.058 & 0.675 & 0.072 & 0.618 & 0.102 & 0.479 \\
\hline
\end{tabular}

BMI—body mass index, BMC—-bone mineral content.

Analyzing the associations between myokine levels and nutritional parameters, we observed that myostatin concentration was negatively correlated with the percentage of energy from protein $(r=-0.338, p=0.014)$, dietary calcium $(r=-0.278, p=0.046)$, and vitamin $\mathrm{A}(\mathrm{r}=-0.304, p=0.028)$ intakes in vegetarian children. In the omnivores, myostatin level was inversely correlated with dietary vitamin $C(r=-0.306, p=0.041)$ and vitamin $E$ $(\mathrm{r}=-0.343, p=0.021)$ intakes. No statistically significant correlations between irisin levels and nutritional data in either study group were found. After Bonferroni corrections, only the correlation between myostatin and omentin levels remained significant at $p<0.002$, both in vegetarians and omnivores.

Multivariate analysis showed that four variables are independent predictors of the myostatin level in children on a vegetarian diet (Table 5). The final model explained 33.3\% of the variability of this myokine according to the corrected $\mathrm{R}^{2}$ determination coefficient. We observed that serum myostatin was strongly positively related to omentin levels $(p<0.001)$ and dietary vitamin $\mathrm{E}$ intake $(p=0.003)$. We also noticed that two factors (dietary calcium and vitamin $B_{12}$ ), which showed a weak relationship with the myostatin level in a simple correlation analysis, were statistically significant $(p=0.013$ and $p=0.023$, respectively) in this model. 
Table 5. Multivariate regressions of myostatin with independent variables in the groups of vegetarians and omnivores.

\begin{tabular}{|c|c|c|c|c|c|c|}
\hline \multirow{3}{*}{ Independent Variables } & \multicolumn{3}{|c|}{ Regression Parameters } & \multirow{3}{*}{$\mathbf{t}$} & \multirow{3}{*}{ p1 p2 } & \multirow{3}{*}{$\Delta \mathbf{R}^{2}$} \\
\hline & \multicolumn{2}{|c|}{ Unstandardized } & \multirow{2}{*}{$\frac{\text { Standardized }}{\beta}$} & & & \\
\hline & B & SE & & & & \\
\hline \multicolumn{7}{|c|}{ Vegetarians } \\
\hline Omentin & 0.0003 & 0.0001 & 0.437 & 3.746 & 0.0000 .000 & 0.130 \\
\hline Dietary calcium & -0.0005 & 0.0002 & -0.301 & -2.234 & 0.0300 .013 & 0.128 \\
\hline Dietary vitamin E & 0.0293 & 0.0097 & 0.406 & 3.012 & 0.0040 .003 & 0.066 \\
\hline Dietary vitamin $B_{12}$ & -0.1024 & 0.0474 & -0.327 & -2.159 & 0.0360 .023 & 0.061 \\
\hline \multicolumn{7}{|c|}{$\mathrm{R}^{2}$ crude $=0.385 ; \mathrm{R}^{2}$ adjusted $=0.333$} \\
\hline \multicolumn{7}{|c|}{ Omnivores } \\
\hline Omentin & 0.0003 & 0.0001 & 0.359 & 3.038 & 0.0050 .001 & 0.115 \\
\hline Fat (\%) & 0.0612 & 0.0118 & 0.958 & 5.168 & 0.0000 .000 & 0.163 \\
\hline Fat/lean & -2.4221 & 0.7434 & -0.588 & -3.258 & 0.0030 .000 & 0.090 \\
\hline Total energy intake & -0.0002 & 0.0001 & -0.255 & -2.159 & 0.0380 .011 & 0.063 \\
\hline Dietary vitamin D & -0.0327 & 0.0117 & -0.350 & -2.806 & 0.0080 .002 & 0.076 \\
\hline Dietary vitamin $B_{12}$ & 0.0495 & 0.0218 & 0.302 & 2.273 & 0.0300 .013 & 0.060 \\
\hline
\end{tabular}

B-unstandardized regression coefficient; SE—standard error; $\beta$-standardized regression coefficient; $p 1$-significance in ordinary linear regression model; 2 2-significance in generalized linear model (GLM); $\Delta R^{2}$ —change in $R^{2}$; constant was included.

Six independent variables, which explain almost half of the myostatin variability $(48.6 \%)$, were qualified to the multifactor model in the omnivorous group. Serum myostatin was strongly, positively correlated to omentin levels $(p=0.001)$ and body fat percentage $(p<0.001)$ and weakly with dietary vitamin $\mathrm{B}_{12}(p=0.013)$. Additionally, we showed that myostatin level was negatively related with the fat/lean ratio $(p<0.001)$, total energy intake $(p=0.011)$, and dietary vitamin D intake $(p=0.002)$. Attention should be paid to myostatin predictors, the effects of which were revealed only in multivariate analysis, with a weak correlation in simple correlation analyses (vitamin $D$, vitamin $B_{12}$, and fat/lean ratio).

In the model estimated for the combined group (Table S1 in the Supplementary Materials), the main effect of omentin, calcium, and vitamin E, and two 2-way interactions between the diet group and vitamin $\mathrm{B}_{12}$ and vitamin $\mathrm{E}$, respectively, were significant. The relationship between theoretical myostatin based on regression models and dietary vitamin $\mathrm{B}_{12}$ in the two groups of children is shown in Figure 1.

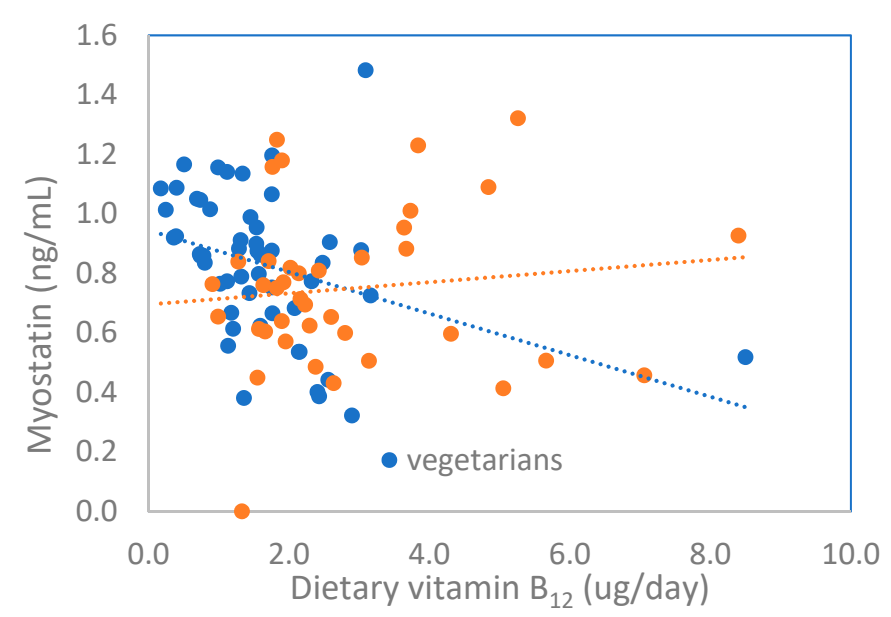

Figure 1. Scatter plot of theoretical myostatin estimated from regression model (Table 5) versus dietary vitamin $B_{12}$ in vegetarian and omnivorous children. 
Analogous models, in which the dependent variable was irisin, were characterized by a weaker adjustment level and contained less predictors (Table 6).

Table 6. Multivariate regressions of irisin with independent variables in the groups of vegetarians and omnivores.

\begin{tabular}{|c|c|c|c|c|c|c|}
\hline \multirow{3}{*}{ Independent Variables } & \multicolumn{3}{|c|}{ Regression Parameters } & \multirow{3}{*}{$\mathbf{t}$} & \multirow{3}{*}{ p1 p2 } & \multirow{3}{*}{$\Delta \mathbf{R}^{2}$} \\
\hline & \multicolumn{2}{|c|}{ Unstandardized } & \multirow{2}{*}{$\frac{\text { Standardized }}{\beta}$} & & & \\
\hline & B & SE & & & & \\
\hline \multicolumn{7}{|c|}{ Vegetarians } \\
\hline $\mathrm{BMC}$ & -0.0010 & 0.0003 & -0.469 & -3.616 & 0.0010 .000 & 0.158 \\
\hline Total energy intake & 0.0002 & 0.0001 & 0.279 & 2.152 & 0.0360 .043 & 0.073 \\
\hline \multicolumn{7}{|c|}{$\mathrm{R}^{2}$ crude $=0.230 ; \mathrm{R}^{2}$ adjusted $=0.199$} \\
\hline \multicolumn{7}{|c|}{ Omnivores } \\
\hline Omentin & 0.0004 & 0.0001 & 0.406 & 2.663 & 0.0120 .002 & 0.121 \\
\hline Dietary manganese & -0.0839 & 0.0450 & -0.284 & -1.863 & 0.0710 .013 & 0.077 \\
\hline \multicolumn{7}{|c|}{$\mathrm{R}^{2}=0.198 ; \mathrm{R}^{2}$ adjusted $=0.153$} \\
\hline
\end{tabular}

B-unstandardized regression coefficient; SE—standard error; $\beta$ —standardized regression coefficient; $\mathrm{p} 1$-significance in ordinary linear regression model; p2-significance in generalized linear model (GLM); $\Delta \mathrm{R}^{2}$ —change in $\mathrm{R}^{2}$; constant was included.

In the vegetarians, BMC and total energy intake explained $19.9 \%$ of the variability of irisin; however, in the omnivores, two factors, omentin and dietary manganese, explained $15.3 \%$ of the variability of irisin. Serum omentin level turned out to be the main predictor $(p=0.002)$. The final model also included dietary manganese intake, which explained $7.7 \%$ of the variability of irisin.

The introduction of two variables such as leptin and adiponectin into the models (Tables 5 and 6 ) did not confirm that these factors independently affected the variability of myokines (myostatin and irisin).

The specification of the above four models was checked by a different estimation method, taking into account the skewness of the distribution of the two dependent variables. The inference concerning the significance of the previously identified predictors had not changed. Moreover, in relation to the association between dietary manganese intake and serum irisin level in the control group, the significance level of the regression parameter decreased from 0.071 to 0.013 .

In the model estimated for the combined group (Table S2 in the Supplementary materials), the main effect of BMC and energy intake was significant, while the diet group and omentin remained insignificant. However, two significant 2-way interactions between the diet group by omentin and BMC (respectively) were found.

\section{Discussion}

The main finding of the present study was that prepubertal children consuming vegetarian and omnivorous diets had comparable serum concentrations of myokines (myostatin, irisin) and selected adipokines (visfatin, omentin). Similar to our previously report [28] concerning classical adipokines, the level of leptin was significantly lower in vegetarians than in omnivores; however adiponectin concentration was comparable between groups. There were also significant associations between myokine and adipokine levels, suggesting cross-talk between skeletal muscle and fat tissue. The strongest was a positive correlation between serum myostatin and omentin concentrations observed in simple correlation analysis and revealed in multivariate regression models in both of the studied groups of children. There were no significant correlations between myokines and leptin as well as adiponectin levels.

The interpretation of myokines and adipokine levels in regards to their clinical use in pediatrics is difficult because of the limited amount of research in this field and a relative lack of reference values of these parameters for children and adolescents. The literature 
contains the normal values for well-known adipokines, such as leptin and adiponectin, in healthy children, but little is known about the normal values of visfatin, omentin, or myokines in the pediatric population [29-33]. It is difficult to compare the serum myokine levels between studies, because the reported levels varied greatly due to the use of different methods and research carried out in different populations and age groups. Han et al. [34] observed the myostatin value to be $12.3 \pm 3.6 \mathrm{ng} / \mathrm{mL}$ in healthy young males. Additionally, Lakshman et al. [35] reported that the serum concentration of myostatin was $8.0 \pm 2.3 \mathrm{ng} / \mathrm{mL}$ in young men, with a tendency to be lower in older people. In a group of healthy adults, Yalcin et al. [36] found that the serum myostatin level was $7004.8 \pm 677.5 \mathrm{pg} / \mathrm{mL}$ and the irisin level was $625.1 \pm 128.6 \mathrm{ng} / \mathrm{mL}$ in healthy Turkish adults. Elizondo-Montemayor et al. [32] assessed irisin levels in small groups of Mexican children and found significantly lower irisin concentrations in the underweight group $(164.3 \pm 5.95 \mathrm{ng} / \mathrm{mL})$ than in the normal weight group $(185.29 \pm 2.62 \mathrm{ng} / \mathrm{mL})$ and the obese group (182.80 $\pm 5.58 \mathrm{ng} / \mathrm{mL})$. Similarly to the current study, Colaianni et al. [33] observed a serum irisin value of $2.59 \pm 1.15 \mathrm{ng} / \mathrm{mL}$ in a group of 34 healthy Italian children aged $9.8 \pm 3.2$ years.

Concerning Nampt visfatin, Nurten et al. [31] reported that median values of this adipokine were: $1.8 \mathrm{ng} / \mathrm{mL}$ in healthy children aged $9.6 \pm 4.3$ years and $1.4 \mathrm{ng} / \mathrm{mL}$ in children aged $13.2 \pm 3.9$ years. Additionally, median serum concentrations of omentin were $325.8 \mathrm{ng} / \mathrm{mL}$ and $290.9 \mathrm{ng} / \mathrm{mL}$ in the above groups of children. These values are similar to those in the current study, and the researchers used the same ELISA kits to determine these adipokines. It is important to establish the secretory profile of myokines and adipokines and to understand their role in the link between skeletal muscle, fat tissues, and other organs.

In our study, despite the lack of statistical differences between myokines and adipokines in the two studied groups, there was a trend towards an increase in values of myostatin and omentin by about $30 \%$, Nampt visfatin by $20 \%$, and irisin by $10 \%$ in vegetarians compared with omnivores. Analyzing the correlations, we showed that there were no significant relations between myostatin and the anthropometric parameters in both studied groups of children, except for a positive correlation (revealed in the multivariate regression model) between myostatin and body fat percentage in the omnivorous group. Additionally, irisin concentration did not correlate with body composition parameters, except for weak correlations with lean mass and bone mineral content in the vegetarian group. Our results are in line with other studies conducted in adults [37].

It is important to expand the knowledge of how tissues of great metabolic importance, such as skeletal muscle and adipose tissue, contribute synergistically to the maintenance of body homeostasis [8,38]. Myokines play a role in restoring a healthy cellular environment, reducing low-grade inflammation and thereby preventing metabolic related diseases. In view of that, the pleiotropic effects of myokines on multiple tissues lead to energy homeostasis. The muscle-adipose axis has an important effect in maintaining a balanced ratio of skeletal muscle to fat and thus may play a key role in the modulation of body composition [39]. Myokines and adipokines appear to be involved in autocrine/paracrine interactions within the muscles as well as adipose and other tissues. In this context, the strong positive association between myostatin and omentin levels observed in our vegetarians revealed cross-talk between skeletal muscle and fat tissues. We suggested that omentin, similar to adiponectin, has a metabolic protective effect on skeletal muscle, as it promotes glucose and fatty acid homeostasis $[40,41]$. The potential role of another adipokine, visfatin, in muscle metabolism has been discussed, but thus far final conclusions cannot be drawn.

Other metabolic mechanisms such as inflammation are involved in the development of muscle disorders. In our previous study, we demonstrated higher ratios of antiinflammatory to pro-inflammatory adipokines in children consuming a vegetarian diet compared with omnivores [28]. In view of that, strong positive association between 
omentin (adipokine with anti-inflammatory properties) with myostatin levels could indicate a favorable anti-inflammatory status observed in our studied children.

Various factors, including nutrients, may influence muscle and adipose tissue. In the present study, myostatin significantly correlated with the percentage of energy from protein, dietary calcium, and vitamin A in vegetarians. Massive amounts of energy were utilized for muscle protein synthesis (MPS) and motor function under both resting and exercise conditions. Not only dietary protein quality but also quantity was an important factor impacting MPS for building and repairing muscle tissues [42]. Branched-chain amino acids, such as leucine, isoleucine, and valine, were particularly important. These amino acids were more concentrated in animal-based protein compared with plant proteins [43] Additionally, the timing and distribution of protein consumption through the day and the digestion and absorption rates of different proteins can also alter and impact muscle protein synthesis.

Minerals and vitamins can promote the growth and repair of skeletal muscle. Nutrients from plant and animal sources have differing bioavailability. In our study, vegetarians as well as omnivores had lower calcium and vitamin D intake (calcium insufficiency in $80 \%$ of vegetarians and $65 \%$ of omnivores, vitamin D insufficiency in about $90 \%$ vegetarians and $80 \%$ omnivores) according to the recommendations [44]. It is widely known that vegetarians are at risk of vitamin $B_{12}$ deficiency because this compound is mainly found in animal products $[45,46]$. In our study, about $25 \%$ of the children on a vegetarian diet had insufficient vitamin $B_{12}$ intake, while all omnivores had adequate dietary intake of this vitamin.

Plant-based diets rich in fruits and vegetables are characterized by a higher intake of antioxidants that play an important role in protecting cells from reactive oxygen species damage. In the present study, we noted a higher dietary intake of vitamin $C$, the main water soluble antioxidant, in vegetarians. In addition, vegetarians had increased intakes of manganese, which is an essential constituent of SOD-1 (superoxide dismutase 1), the most important antioxidative enzyme. A higher dietary intake of nutrients with antioxidant properties in the vegetarian diet provides health benefits [47,48]. It is difficult to explain the individual dietary intake of nutrients because they act synergistically to maintain body homeostasis. The study of Gauze-Gnagne et al. [49], conducted on rats, assessed the influence of various high-fat diets rich in palm oil or olive oil on the modulation of myokine gene expression. The authors reported that high-fat diets (dependending on the type of fat used) can differentially modulate the expression of some myokines (decreased irisin and increased myonectin levels).

To the best of our knowledge, this is the first report on serum myokines in children consuming a vegetarian diet. This represents a first attempt to understand the link between the interaction of myokines and adipokines and the role of diet in the regulation of important metabolic functions; however, further investigations are needed to fully understand the mechanisms.

Some limitations should be mentioned. Firstly, our conclusion was established based on a limited number of samples and needs to be further confirmed in a larger sample size. However, our studied groups of children were comparable in terms of age, Tanner stage, and body composition. Secondly, we did not determine other novel myokines (e.g., myonectin) but we are planning assessments of a wide range of myokines, such as interleukins, myonectin, and decorin in our future study conducted on children following different dietary styles. Thirdly, our results were based on single measurements of serum myokine and adipokine concentrations in children and therefore may not reflect the longterm exposure of these proteins. Additionally, we analyzed only serum levels of myokines and did not assess its expression by the skeletal muscles. However, we provided unique determination of myokines in prepubertal children with different types of diet for the first time. Fourthly, we did not provide an exact analysis of the physical activity of the studied children, but both groups were comparable regarding MVPA and VPA. We assessed the percentage of energy from protein and did not analyze the dietary amino acid intake in 
the studied groups of children; however, we are planning such assessments in our next study. Finally, the cross-sectional nature of our study does not permit causality statements. However, we believe that our results may create basic knowledge for further studies evaluating the possible role of diet on the myokine and adipokine profiles, inflammation, and metabolic status.

To conclude, consuming a vegetarian diet, particularly its lacto-ovo-vegetarian version did not influence the serum levels of myokines and adipokines such as adiponectin, visfatin, and omentin in the prepubertal period. However, leptin level was significantly lower in vegetarians compared with omnivores. The observed significant positive correlations between serum myostatin and omentin levels may represent a link between muscle and fat tissues. In view of this, omentin is an adipokine with anti-inflammatory properties, and its strong positive association with myostatin could indicate a favorable anti-inflammatory status. Further investigations could be important to fully understand the myokine/adipokine-related mechanisms involved in the cross-talk between skeletal muscle, adipose tissues, and nutrition.

Supplementary Materials: The following are available online at https://www.mdpi.com/article/10 $.3390 /$ jcm10173995/s1, Table S1: Multivariate generalized linear model of myostatin in the combined group of vegetarians and omnivores with main effect and 2-way interaction with the diet group, Table S2. Multivariate generalized linear model of irisin in the combined group of vegetarians and omnivores with main effect and 2-way interaction with the diet group.

Author Contributions: J.A. conceived and designed the experiments; J.A., M.C., and J.G. gathered the biochemical measurements and analyzed the results; G.R. and W.K. assessed the anthropometric parameters and the diets of the studied children; M.S. calculated the basic nutrient values in average daily food ratios; J.M. undertook statistical analysis and data interpretation; J.A. wrote the paper; M.C., J.G., and M.O. reviewed the manuscript. All authors have read and agreed to the published version of the manuscript.

Funding: This research did not receive any specific grant from funding agencies in the public, commercial, or not-for-profit sectors.

Institutional Review Board Statement: The study was conducted according to the guidelines of the Declaration of Helsinki, and approved by the Ethics Committee of the Institute of Mother and Child (protocol code 12/2017, date of approval 12 March 2017).

Informed Consent Statement: Written informed consent has been obtained from the parents of patients to published this paper.

Acknowledgments: The authors are grateful to all the children and parents who took part in the study and would like to thank the staff of the Department of Internal Medicine, Endocrinology, and Diabetology at the Central Clinical Hospital MSW in Warsaw for performing the full body DXA scans. We also thank Anna Ambroszkiewicz for her help with checking the English language.

Conflicts of Interest: The authors declare no conflict of interest.

\section{References}

1. Kersting, M.; Alexy, U.; Schurmann, S. Critical dietary habits in early childhood: Principles and practice. World Rev. Nutr. Diet 2016, 115, 24-35. [CrossRef] [PubMed]

2. Baroni, L.; Goggi, S.; Battino, M. Planning well-balanced vegetarian diets in infants, children, and adolescents: The VegPlate Junior. J. Acad. Nutr. Diet 2018. [CrossRef] [PubMed]

3. Van Winckel, M.; Vande Velde, S.; De Bruyne, R.; Van Biervliet, S. Clinical practice: Vegetarian infant and child nutrition. Eur. J. Pediatr. 2011, 170, 1489-1494. [CrossRef]

4. Hovinen, T.; Korkalo, L.; Freese, R.; Skaffari, E.; Isohanni, P.; Niemi, M.; Nevalainen, J.; Gylling, H.; Zamboni, N.; Erkkola, M.; et al. Vegan diet in young children remodels metabolism and challenges the statuses of essential nutrients. EMBO Mol. Med. 2021, 13, e13492. [CrossRef]

5. Schurmann, S.; Kersting, M.; Alexy, U. Vegetarian diets in children: A systematic review. Eur. J. Nutr. 2017, 56, 1797-1817. [CrossRef]

6. Craig, W.J.; Mangels, A.R. Position of the American Dietetic Association: Vegetarian diets. J. Am. Diet Assoc. 2009, 109, 1266-1282. 
7. Melina, V.; Craig, W.; Levin, S. Position of the Academy of Nutrition and Dietetics: Vegetarian diets. J. Acad. Nutr. Diet 2016, 116, 1970-1980. [CrossRef]

8. Chung, H.S.; Choi, K.M. Organokines in disease. Adv. Clin. Chem. 2020, 94, 261-321. [CrossRef]

9. Bluher, M. Clinical relevance of adipokines. Diabetes Metab. J. 2012, 36, 317-327. [CrossRef] [PubMed]

10. Walsh, F.S.; Celeste, A.J. Myostatin: A modulator of skeletal-muscle stem cells. Biochem. Soc. Trans. 2005, 33, 1513-1517. [CrossRef] [PubMed]

11. Burch, P.M.; Pogoryelova, O.; Palandra, J.; Goldstein, R.; Bennett, D.; Fitz, L.; Guglieri, M.; Bettolo, C.M.; Straub, V.; Evangelista, T.; et al. Reduced serum myostatin concentrations associated with genetic muscle disease progression. J. Neurol. 2017, 264, 541-553. [CrossRef] [PubMed]

12. Long, K.K.; O'Shea, K.M.; Khairallah, R.J.; Howell, K.; Paushkin, S.; Chen, K.S.; Cote, S.M.; Webster, M.T.; Stains, J.P.; Treece, E.; et al. Specific inhibition of myostatin activation is beneficial in mouse models of SMA therapy. Hum. Mol. Genet. 2019, 28, 1076-1089. [CrossRef]

13. McFarlane, C.; Hui, G.Z.; Amanda, W.Z.; Lau, H.Y.; Lokireddy, S.; Xiaojia, G.; Mouly, V.; Butter-Browne, G.; Gluckman, P.D.; Sharma, M.; et al. Human myostatin negatively regulates human myoblast growth a differentiation. Am. J. Physiol. Cell Physiol. 2011, 301, C196-C203. [CrossRef]

14. Martinez Munoz, I.Y.; Camarillo Romero, E.D.S.; Garduno Garcia, J.J. Irisin a novel metabolic biomarker: Present knowledge and future directions. Int. J. Endocrinol. 2018, 2018, e7816806. [CrossRef]

15. Park, H.S.; Kim, H.C.; Zhang, D.; Yeom, H.; Lim, S.K. The novel myokine irisin: Clinical implications and potential role as a biomarker for sarcopenia in postmenopausal women. Endocrine 2019, 64, 341-348. [CrossRef] [PubMed]

16. Boström, P.; Wu, J.; Jedrychowski, M.P.; Korde, A.; Ye, L.; Lo, J.C.; Rasbach, K.A.; Boström, E.A.; Choi, J.H.; Long, J.Z.; et al. A PGC1- $\alpha$-dependent myokine that drives brown-fat-like development of white fat and thermogenesis. Nature 2012, 481, 463-468. [CrossRef]

17. Roca-Rivada, A.; Castelao, C.; Senin, L.L.; Landrove, M.O.; Baltar, J.; Belén Crujeiras, A.; Seoane, L.M.; Casanueva, F.F.; Pardo, M. FNDC5/irisin is not only a myokine but also an adipokine. PLoS ONE 2013, 8, e60563. [CrossRef]

18. Buccoliero, C.; Oranger, A.; Colaianni, G.; Pignataro, P.; Zerlotin, R.; Lovero, R.; Errede, M.; Grano, M. The effect of irisin on bone cells in vivo and in vitro. Biochem. Soc. Trans. 2021, 49, 477-484. [CrossRef] [PubMed]

19. Martos-Moreno, G.A.; Kratzsch, J.; Korner, A.; Barrios, V.; Hawkins, F.; Kiess, W.; Argente, J. Serum visfatin and vaspin levels in prepubertal children: Effect of obesity and weight loss after behavior modifications on their secretion and relationship with glucose metabolism. Int. J. Obes. 2011, 35, 1355-1362. [CrossRef]

20. Revollo, J.R.; Grimm, A.A.; Imai, S. The regulation of nicotinamide adenine dinucleotide biosynthesis by Nampt/PBEF/visfatin in mammals. Curr. Opin. Gastroenterol. 2007, 23, 164-170. [CrossRef]

21. Schaffler, A.; Neumeier, M.; Herfarth, H.; Furst, A.; Scholmerich, J.; Buchler, C. Genomic structure of human omentin, a new adipocytokine expressed in omental adipose tissue. Biochem. Biophys. Acta 2005, 1732, 96-102. [CrossRef] [PubMed]

22. Jaikanth, C.; Gurumurthy, P.; Cherian, K.M.; Indhumathi, T. Emergence of omentin as a pleiotropic adipokine. Exp. Clin. Endocrinol. Diabetes 2013, 121, 377-383. [CrossRef] [PubMed]

23. Severinsen, M.C.K.; Pedersen, B.K. Muscle-organ crosstalk: The emerging roles of myokines. Endocrine Rev. 2020, 41, 594-609. [CrossRef]

24. Leal, L.G.; Lopes, M.A.; Batista, M.L. Physical exercise-induced myokines and muscle-adipose tissue crosstalk: A review of current knowledge and the implications for health and metabolic diseases. Front. Physiol. 2018, 9, e1307. [CrossRef] [PubMed]

25. Appleby, P.N.; Key, T.J. The long-term health of vegetarians and vegans. Proc. Nutr. Soc. 2016, 75, 287-293. [CrossRef]

26. Kahleova, H.; Levin, S.; Barnard, N. Cardio-metabolic benefits of plant-based diets. Nutrients 2017, 9, 848. [CrossRef]

27. Ambroszkiewicz, J.; Klemarczyk, W.; Mazur, J.; Gajewska, J.; Rowicka, G.; Strucińska, M.; Chełchowska, M. Serum hepcidin and soluble transferrin receptor in the assessment of iron metabolism in children on a vegetarian diet. Biol. Trace Elem. Res. 2017, 180, 182-190. [CrossRef] [PubMed]

28. Ambroszkiewicz, J.; Chełchowska, M.; Rowicka, G.; Klemarczyk, W.; Strucińska, M.; Gajewska, J. Anti-inflammatory and pro-inflammatory adipokine profile in children on vegetarian and omnivorous diets. Nutrients 2018, 10, 1241. [CrossRef]

29. Lausten-Thomsen, U.; Christiansen, M.; Louise Hedley, P.; Esmann Fonvig, C.; Stjernholm, T.; Pedersen, O.; Hansen, T.; Holm, J.C. Reference values for serum leptin in healthy non-obese children and adolescents. Scand. J. Clin. Lab. Investig. 2016, 76, 561-567. [CrossRef]

30. Erhardt, E.; Foraita, R.; Pigeot, I.; Barba, G.; Veidebaum, T.; Tornaritis, M.; Michels, N.; Eiben, G.; Ahrens, W.; Moreno, L.A.; et al. Reference values for leptin and adiponectin in children below the age of 10 based on the IDEFICS cohort. Int. J. Obes. 2014, 38, S32-S38. [CrossRef]

31. Nurten, E.; Vogel, M.; Kapellen, M.; Richter, S.; Garten, A.; Penke, M.; Schuster, S.; Korner, A.; Kiess Kratzsch, J. Omentin-1 and NAMPT serum concentrations are higher and C, K-18 levels are lower in children and adolescents with type 1 diabetes when compared to healthy age, sex and BMI matched controls. J. Pediatr. Endocrinol. Metab. 2018, 31, 959-969. [CrossRef]

32. Elizondo-Montemayor, L.; Mendoza-Lara, G.; Gutierrez-DelBosque, G.; Peschard-Franco, M.; Nieblas, B.; Garcia-Rivas, G. Relationship of circulating irisin with body composition, physical activity, and cardiovascular and metabolic disorders in the pediatric population. Int. J. Mol. Sci. 2018, 19, 3727. [CrossRef] 
33. Colaianni, G.; Faienza, M.F.; Sanesi, L.; Brunetti, G.; Pignataro, P.; Lippo, L.; Bortolotti, S.; Storlino, G.; Piacente, L.; D’Amato, G.; et al. Irisin serum levels are positively correlated with bone mineral status in a population of healthy children. Pediatr. Res. 2019, 85, 484-488. [CrossRef]

34. Han, D.S.; Huang, C.H.; Chen, S.Y.; Yang, W.S. Serum reference value of two potential doping candidates-myostatin and insulin-like growth factor-I in the healthy young male. J. Int. Soc. Sports Nutr. 2017, 14, e2. [CrossRef] [PubMed]

35. Lakshman, K.M.; Bhasin, S.; Corcoran, C.; Collins-Racie, L.A.; Tchistiakova, L.; Forlow, S.B.; St Ledger, K.; Burczynski, M.E.; Dorner, A.J.; Lavallie, E.R. Measurement of myostatin concentrations in human serum: Circulating concentrations in young and older men and effects of testosterone administration. Mol. Cell Endocrinol. 2009, 302, 26-32. [CrossRef] [PubMed]

36. Yalcin, M.M.; Akturk, M.; Tohma, Y.; Cerit, E.T.; Altinova, A.E.; Arslan, E.; Yetkin, I.; Toruner, F.B. Irisin and myostatin levels in patients with Graves' disease. Arch. Med. Res. 2016, 47, 471-475. [CrossRef]

37. Ma, Y.; Zhang, H.; Ou, Y.; Zhang, Z.; Li, S.; Wu, F.; Sheng, Z.; Liao, E. Serum myostatin in central south Chinese postmenopausal women: Relationship with body compasition, lipids and bone mineral density. Endocr. Res. 2016, 41, 223-228. [CrossRef]

38. Stanford, K.I.; Goodyear, L. Muscle-Adipose Tissue Cross Talk. J. Cold. Spring Harb. Perspect. Med. 2018, 8, a029801. [CrossRef] [PubMed]

39. Li, F.; Li, Y.; Duan, Y.; Hu, C.A.A.; Tang, Y.; Yin, Y. Myokines and adipokines: Involvement in the crosstalk between skeletal muscle and adipose tissue. Cytokine Growth Factor Rev. 2017, 33, 73-82. [CrossRef]

40. Liu, Y.; Sweeney, G. Adiponectin action in skeletal muscle. Best Pract. Res. Clin. Endocrinol. Metab. 2014, 28, 33-41. [CrossRef]

41. Fiaschi, T.; Magherini, F.; Gamberi, T.; Modesti, P.A.; Modesti, A. Adiponectin as a tissue regenerating hormone: More than a metabolic function. Cell Mol. Life Sci. 2014, 71, 1917-1925. [CrossRef] [PubMed]

42. Lynch, H.; Johnston, C.; Wharton, C. Plant-based diets: Considerations for environmental impact, protein quality, and exercise performance. Nutrients 2018, 10, 1841. [CrossRef] [PubMed]

43. Wolfe, R.R. Branched-chain amino acids and muscle protein synthesis in humans: Myth or reality? J. Int. Soc. Sports Nutr. 2017, 14, e30. [CrossRef]

44. Jarosz, M.; Traczyk, I.; Rychlik, E. Energia. In Normy Żywienia Dla Populacji Polskiej-Nowelizacja; Jarosz, M., Ed.; National Food and Nutrition Institute: Warsaw, Poland, 2012; pp. 18-32.

45. Herrmann, W.; Schorr, H.; Obeid, R.; Geisel, J. Vitamin B-12 status, particularly holotranscobalamin II and methylmalonic acid concentrations, and hyperhomocysteinemia in vegetarians. Am. J. Clin. Nutr. 2003, 78, 131-136. [CrossRef] [PubMed]

46. Watanabe, F.; Bito, T. Vitamin B12 sources and microbial interaction. Exp. Biol. Med. 2018, 243, 148-158. [CrossRef]

47. Funtikova, A.N.; Navarro, E.; Bawaked, R.A.; Fito, M.; Schroder, H. Impact of diet on cardiometabolic health in children and adolescents. Nutrition J. 2015, 14, 118. [CrossRef]

48. Craddock, J.C.; Neale, E.P.; Peoples, G.E.; Probst, Y.C. Vegetarian-based dietary patterns and their relation with inflammatory and immune biomarkers: A systemic review and meta-analysis. Adv. Nutr. 2019, 10, 433-451. [CrossRef]

49. Gauze-Gnagne, C.; Raynaud, F.; Djohan, Y.F.; Lauret, C.; Feillet-Coudray, C.; Coudray, C.; Monde, A.; Koffi, G.; Morena, M.; Camara-Cisse, M.; et al. Impact of diets rich in olive oil, palm oil or lard on myokine expression in rats. Food Funct. 2020, 11, 9114-9128. [CrossRef] 